\title{
¿Cómo llevar la poesía de Gloria Fuertes al aula de Primaria? Una propuesta de innovación docente a través del videopoema
}

\author{
How to bring Gloria Fuertes' \\ poetry into the primary \\ school classroom? A proposal \\ for teaching innovation \\ through the video poem
}

MARÍA SÁNCHEZ-RAMOS

ORCID: https://orcid.org/0000-0002-9903-116X

Universidad de Sevilla

Dpto. Literatura Española e Hispanoamericana msanchez103@us.es

DOI: http://dx.doi.org/10.12795/9788447231003.064 Pp.: 1348-1369 


\section{Descripción del contexto del Ciclo de Mejora}

El presente Ciclo de Mejora en el Aula ha sido desarrollado en la asignatura Literatura Española del Grado en Educación Primaria. Se trata de una asignatura obligatoria que se imparte en el primer cuatrimestre del 40 curso del Grado y que está dividida en clases teóricas y clases prácticas. Mi docencia se imparte en el subgrupo número 12 de prácticas, que cuenta con 13 alumnos y alumnas. Debido a la crisis sanitaria por la covid-19 en la que se ha desarrollado este CIMA, este grupo de estudiantes recibe su formación práctica de manera totalmente asíncrona ya que, además, las subdivisiones de la clase afectan al calendario de clases, haciendo imposible que este alumnado en concreto reciba las sesiones de la parte práctica de modo síncrono por incompatibilidad horaria con otras materias.

La tradición docente de la asignatura hace que sea dificil mantener una continuidad docente, pues se vincula tradicionalmente al personal predoctoral del Dpto. de Literatura Española e Hispanoamericana, el cual es bastante numeroso. Esto hace que sea una asignatura con mucha fluctuación de profesorado, que además divide sus créditos en 4 ECTS para la teoría y 1,7 ECTS para la práctica. Asimismo, se trata de una asignatura muy fragmentada ya que varios docentes comparten grupos teóricos e incluso los grupos prácticos, siendo por tanto la comunicación entre el profesorado una parte esencial para la correcta impartición de la materia, intentando que estas particiones ajenas a nuestra voluntad afecten lo menos posible al alumnado. La parte práctica de la materia Literatura Española se divide en: género dramático, lírico y narrativo. En anteriores cursos se ha optado por proponer la elaboración de un portafolio de actividades centradas en el análisis de textos.

La parte práctica cuenta un 30\% en la calificación final del alumnado mientras que la teórica, un 70\%. Dentro de las clases prácticas, se diseña un portafolio dividido en 8 actividades ( 4 puntos) + 3 trabajos finales por módulo drama, poesía y narrativa - (6 puntos). 
El CIMA se ha aplicado a lo largo de las sesiones del segundo módulo práctico: el género lírico, cuyo trabajo final consiste en una propuesta de innovación didáctica para llevar la poesía al aula de Primaria a través del videopoema.

\section{Mapa de contenidos y problemas}

El mapa de contenidos y problemas ha sido diseñado para integrar y cohesionar diversos tipos de contenidos sobre el género lírico: contenidos conceptuales o teóricos y contenidos procedimentales intelectuales, sin olvidar aquellos que trabajan los valores y actitudes del alumnado. Por ello, se ha pretendido dotar al contenido a trabajar en clase de una coherencia e interrelación interna con el fin de brindar una panorámica práctica y holística del hecho poético. De este modo, el CIMA se ha organizado en contenidos estructurales e imprescindibles y en contenidos derivados de los mismos con el fin de acercar la poesía al aula de un modo innovador a doble nivel -tanto en el aula universitaria como en el aula de Primaria-. Asimismo, el mapa presenta una serie de problemas fundamentales a resolver por los alumnos y alumnas a través de preguntas atrayentes que, captando su atención, ayuden a involucrarles en su proceso de enseñanza-aprendizaje. Esas preguntas se han visto trasladadas a un cuestionario inicial y final para evaluar las ideas y mapas mentales de los estudiantes antes y después de la aplicación del ciclo. La evolución de estas sus ideas ha sido medida y representada gráficamente mediante las escaleras de aprendizaje (Porlán, 2017). Por otro lado, este mapa de contenidos pretende reivindicar la figura de la poeta Gloria Fuertes, poniendo así en cuestión la mirada androcéntrica que ha configurado la historia de la literatura relegando a las escritoras a los márgenes de la creación literaria (Arriaga, 2020). De este modo, el mapa de contenidos posee una clara apuesta por valores como el feminismo, el pacifismo y la crítica social tan presentes en la obra de Fuertes (De Cascantes, 2017). Ciclos de Mejora en el Aula (2020). Experiencias de Innovación Docente de la US
Esta obra se distribuye con la licencia Creative Commons 


\section{MARÍA SÁNCHEZ-RAMOS}

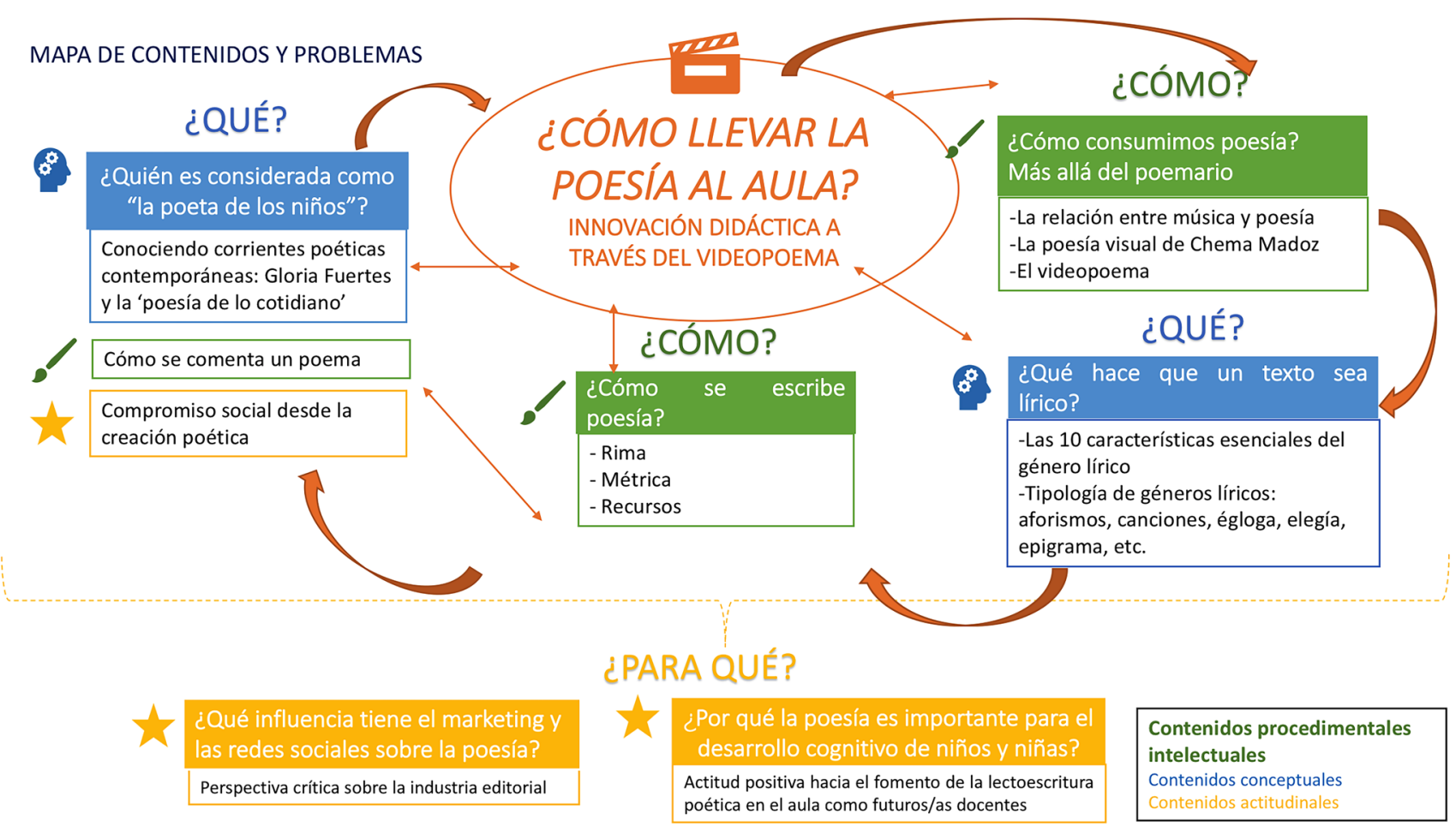

Figura 1. Mapa de contenidos y problemas

Ciclos de Mejora en el Aula (2020). Experiencias de Innovación Docente de la US (c) (i) $\Theta$ Esta obra se distribuye con la licencia Creative Commons cc)

Reconocimiento-NoComercial-SinObraDerivada 
Las cinco sesiones en las que se desarrolla el CIMA tienen por objeto dar las herramientas oportunas al alumnado para resolver el problema planteado que consiste en Llevar la poesía al aula de Primaria a través de la propuesta de innovación didáctica que representa el videopoema. Para ello han de desarrollar conocimientos teórico-prácticos sobre el género lírico que quedarán sintetizados en tareas de: a) escritura, b) comentario y c) reflexión que les permitan orquestar y sintetizar los aprendizajes sobre el género lírico mediante la videocreación literaria. De este modo, se pretende que como futuros docentes adquieran una predisposición positiva hacia la poesía desde un conocimiento útil y pragmático, que les brinde materiales de creación propia para sus unidades didácticas.

\section{Modelo metodológico posible y secuencia de actividades}

El modelo metodológico posible que se plantea en el presente CIMA dista a simple vista del modelo metodológico habitual de la asignatura, el cual consistía en dotar al alumnado de una breve introducción, seguida de nociones teóricas proporcionadas en clase magistral para a continuación abordar una serie de prácticas mediante las que se desarrollaban los trabajos sobre los géneros líricos en un dossier de clase. Por ser este un modelo que presentaba problemas metodológicos se ha propuesto el diseño personal de un nuevo modelo metodológico posible, a medio camino entre el habitual y el ideal. Entre los problemas que presentaba el modelo metodológico tradicional destacan la carente interconexión de las prácticas entre sí y la escasa aplicabilidad entre los conocimientos abordados en clase y el futuro desempeño docente del alumnado como maestros de Primaria. Es por ello por lo que el modelo metodológico posible ha perseguido poner solución a dichos obstáculos estableciendo como premisa fundamental el conocimiento de la literatura para su aplicación Ciclos de Mejora en el Aula (2020). Experiencias de Innovación Docente de la US
Esta obra se distribuye con la licencia Creative Commons 
futura y no como formación estanca aplicada al periodo de validez que la materia disponga meramente en la vida universitaria del alumnado.

Así, el modelo metodológico personal en evolución presentado consiste en las siguientes fases: a) En su inicio se plantea un proceso de introducción a la materia conectado con el sondeo de las ideas previas del alumnado mediante el Cuestionario Inicial mencionado, el cual a su vez está interrelacionado con el Planteamiento del Problema sobre el que giran las distintas sesiones: ¿Cómo llevar la poesía al aula? b) A continuación, se trabajan las ideas de los alumnos y se sigue un ciclo de actividades de contraste teóricas y prácticas que finalizan con el Cuestionario Final y con una actividad reflexiva a modo de Cierre. Todo ello conduce al proyecto final del módulo lírico que, a partir de la creación audiovisual del videopoema, da respuesta al problema articulador del ciclo.

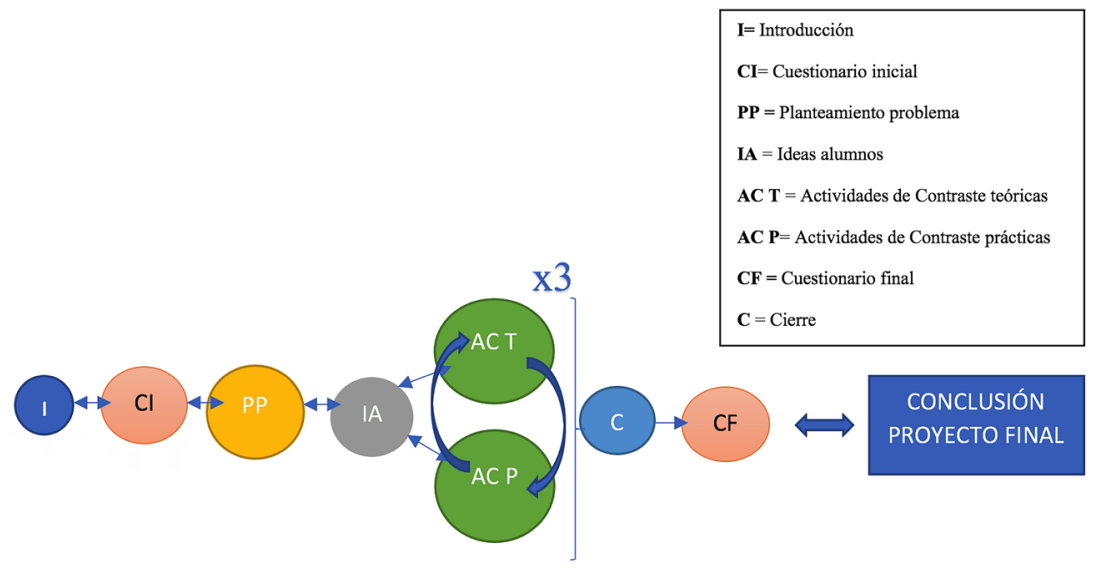

Figura 2. Modelo metodológico posible

A continuación, detallo las actividades realizadas para las cinco sesiones en las q ue se distribuye el CIMA.

Ciclos de Mejora en el Aula (2020). Experiencias de Innovación Docente de la US Esta obra se distribuye con la licencia Creative Commons 
Tabla 1. Secuencia de actividades del ciclo de mejora

\begin{tabular}{|c|c|c|c|c|}
\hline \multicolumn{5}{|l|}{ SESIÓN 1} \\
\hline $\begin{array}{l}\text { TIPO DE } \\
\text { ACTIVIDAD }\end{array}$ & TIEMPO & CONTENIDO & RECURSO & $\begin{array}{l}\text { FASE } \\
\text { DEL } \\
\text { MM }\end{array}$ \\
\hline $\begin{array}{l}\text { Presentación. } \\
\text { Introducción } \\
\text { al módulo del } \\
\text { género lírico }\end{array}$ & $10^{\prime}$ & $\begin{array}{l}\text { Estructura del módulo, modelo } \\
\text { de evaluación, tutorías, flujo de } \\
\text { la información en la modalidad } \\
\text { asíncrona. Se aborda qué vamos a } \\
\text { trabajar, cómo, qué se espera del } \\
\text { alumno y se facilita la planificación } \\
\text { temporal. }\end{array}$ & $\begin{array}{l}\text { Vídeo propio } \\
\text { en Enseñanza } \\
\text { Virtual (EV) }\end{array}$ & । \\
\hline $\begin{array}{l}\text { Cuestionario } \\
\text { inicial: } \\
\text { ¿Qué sabemos } \\
\text { sobre poesía? }\end{array}$ & $30^{\prime}$ & $\begin{array}{l}\text { Sondeo inicial no evaluable para } \\
\text { saber cuál es el punto de partida } \\
\text { del grupo. } \\
\text { Cuestionario para trabajar sobre } \\
\text { las ideas previas del alumnado } \\
\text { en torno a la poesía. Se exploran } \\
\text { cuestiones, entre otras, acerca } \\
\text { de la relevancia del género lírico } \\
\text { en la Educación Primaria; el } \\
\text { conocimiento de autores/as; y } \\
\text { la perspectiva crítica sobre qué } \\
\text { consideramos poesía. }\end{array}$ & $\begin{array}{l}\text { Google Forms } \\
\text { que han de } \\
\text { enviar con } \\
\text { pseudónimo. }\end{array}$ & $\mathrm{Cl}$ \\
\hline $\begin{array}{l}\text { Problema: Crear } \\
\text { un videopoema. }\end{array}$ & - & $\begin{array}{l}\text { Se presenta el proyecto final } \\
\text { del módulo de género lírico. } \\
\text { Se plantea un problema de } \\
\text { intervención en un CEIP concreto. } \\
\text { El alumnado de Primaria presenta } \\
\text { carencias en las destrezas de } \\
\text { lectoescritura y la Junta de } \\
\text { Andalucía financiará un Plan de } \\
\text { Fomento de la Lectoescritura. El } \\
\text { alumnado se pone en la piel de } \\
\text { un maestro Primaria y basa su } \\
\text { diseño didáctico en la creación de } \\
\text { un videopoema. }\end{array}$ & $\begin{array}{l}\text { PDF con el } \\
\text { problema e } \\
\text { instrucciones } \\
\text { en EV }\end{array}$ & PP \\
\hline
\end{tabular}

Ciclos de Mejora en el Aula (2020). Experiencias de Innovación Docente de la US Esta obra se distribuye con la licencia Creative Commons 


\begin{tabular}{|c|c|c|c|c|}
\hline $\begin{array}{l}\text { Hilo de debate: } \\
\text { La poesía, un } \\
\text { arma cargada } \\
\text { de futuro. }\end{array}$ & $40^{\prime}$ & $\begin{array}{l}\text { Con el fin de salvar las distancias } \\
\text { físicas que nos separan, el } \\
\text { alumnado elabora una exploración } \\
\text { colaborativa mediante un hilo } \\
\text { de debate sobre los principales } \\
\text { beneficios de la poesía para niños } \\
\text { y niñas de Primaria. Asimismo, } \\
\text { deben destacar los principales } \\
\text { obstáculos e inconvenientes que } \\
\text { prevén que el docente deberá } \\
\text { enfrentar en el aula. De este modo, } \\
\text { comparten los resultados de su } \\
\text { indagación y crean conclusiones } \\
\text { en común. }\end{array}$ & $\begin{array}{l}\text { Hilo de } \\
\text { debate } \\
\text { colaborativo } \\
\text { en EV }\end{array}$ & IA \\
\hline \multicolumn{5}{|l|}{ SESIÓN 2} \\
\hline $\begin{array}{l}\text { TIPO DE } \\
\text { ACTIVIDAD }\end{array}$ & TIEMPO & CONTENIDO & RECURSO & $\begin{array}{l}\text { FASE } \\
\text { DEL } \\
\text { MM }\end{array}$ \\
\hline $\begin{array}{l}\text { ¿Está la poesía } \\
\text { presente en } \\
\text { nuestro día a } \\
\text { día? }\end{array}$ & $1 \mathrm{~h}$ & $\begin{array}{l}\text { Clase asíncrona en la que la } \\
\text { docente proporcionará las claves } \\
\text { de la interrelación de la poesía } \\
\text { y las artes profundizando en } \\
\text { su relación con la música, la } \\
\text { fotografía (poesía visual de Chema } \\
\text { Madoz) y la videopoesía. }\end{array}$ & Powerpoint EV & $A C T$ \\
\hline $\begin{array}{l}\text { La música en } \\
\text { clave poética }\end{array}$ & $20^{\prime}$ & $\begin{array}{l}\text { Lista de música colaborativa en } \\
\text { Spotify Poemas hechos canciones. } \\
\text { El alumnado pone ejemplos de } \\
\text { poemas hechos canciones a partir } \\
\text { de la clase anterior para completar } \\
\text { el material que les facilito y } \\
\text { compartirlo con el resto del grupo. } \\
\text { De este modo, se ayudan unos a } \\
\text { otros en el proceso de búsqueda } \\
\text { de inspiración para su proyecto } \\
\text { final de videocreación poética. }\end{array}$ & Spotify & $A C P$ \\
\hline \multicolumn{5}{|l|}{ SESIÓN 3} \\
\hline $\begin{array}{l}\text { TIPO DE } \\
\text { ACTIVIDAD }\end{array}$ & TIEMPO & CONTENIDO & RECURSO & $\begin{array}{l}\text { FASE } \\
\text { DEL } \\
\text { MM }\end{array}$ \\
\hline
\end{tabular}

Ciclos de Mejora en el Aula (2020). Experiencias de Innovación Docente de la US Esta obra se distribuye con la licencia Creative Commons 


\begin{tabular}{|c|c|c|c|c|}
\hline $\begin{array}{l}\text { Las } 10 \\
\text { características } \\
\text { fundamentales } \\
\text { del género lírico }\end{array}$ & $1 \mathrm{~h}$ & $\begin{array}{l}\text { Exposición teórica sobre las } \\
\text { características principales del } \\
\text { género lírico y sus tipologías. } \\
\text { Se trata de una clase síncrona } \\
\text { teórica en la que se imparten las } \\
\text { características principales del } \\
\text { género lírico y sus tipologías. } \\
\text { Asimismo, explicaré aspectos } \\
\text { sobre la rima, la métrica y los } \\
\text { recursos básicos de composición. }\end{array}$ & $\begin{array}{l}\text { Blackboard } \\
\text { Collaborate }\end{array}$ & $A C T$ \\
\hline $\begin{array}{l}\text { Taller de } \\
\text { escritura: el } \\
\text { haiku y las } \\
\text { greguerías }\end{array}$ & $20^{\prime}$ & $\begin{array}{l}\text { Los estudiantes se lanzarán a } \\
\text { la escritura poética a través del } \\
\text { haiku -un cercano y sencillo } \\
\text { género poético japonés-y de la } \\
\text { greguería. }\end{array}$ & $\begin{array}{l}\text { Tarea a } \\
\text { entregar en } \\
\text { EV }\end{array}$ & $A C P$ \\
\hline \multicolumn{5}{|l|}{ SESIÓN 4} \\
\hline $\begin{array}{l}\text { TIPO DE } \\
\text { ACTIVIDAD }\end{array}$ & TIEMPO & CONTENIDO & RECURSO & $\begin{array}{l}\text { FASE } \\
\text { DEL } \\
\text { MM }\end{array}$ \\
\hline $\begin{array}{l}\text { La poeta de los } \\
\text { niños }\end{array}$ & 1h & $\begin{array}{l}\text { Clase síncrona de introducción a } \\
\text { la obra y figura de la poeta Gloria } \\
\text { Fuertes. Se ahondó en los valores } \\
\text { de igualdad potenciando la voz de } \\
\text { la autoría femenina en poesía, así } \\
\text { como el compromiso social propio } \\
\text { de la obra de Fuertes. }\end{array}$ & $\begin{array}{l}\text { Blackboard } \\
\text { Collaborate }\end{array}$ & $A C T$ \\
\hline $\begin{array}{l}\text { Comentario de } \\
\text { un poema de } \\
\text { Gloria Fuertes }\end{array}$ & $30^{\prime}$ & $\begin{array}{l}\text { Tarea individual de comentario } \\
\text { de texto a partir del poema 'Nota } \\
\text { autobiográfica' de Gloria Fuertes. }\end{array}$ & $\begin{array}{l}\text { Guía de } \\
\text { comentario } \\
\text { y materiales } \\
\text { sobre la } \\
\text { autora en EV }\end{array}$ & $A C P$ \\
\hline \multicolumn{5}{|l|}{ SESIÓN 5} \\
\hline $\begin{array}{l}\text { TIPO DE } \\
\text { ACTIVIDAD }\end{array}$ & TIEMPO & CONTENIDO & RECURSO & $\begin{array}{l}\text { FASE } \\
\text { DEL } \\
\text { MM }\end{array}$ \\
\hline $\begin{array}{l}\text { Cuestionario } \\
\text { final }\end{array}$ & $30^{\prime}$ & $\begin{array}{l}\text { Cuestionario para evaluar el } \\
\text { progreso del alumnado tras la } \\
\text { aplicación del CIMA. }\end{array}$ & $\begin{array}{l}\text { Google Forms } \\
\text { que han de } \\
\text { enviar con } \\
\text { pseudónimo }\end{array}$ & CF \\
\hline
\end{tabular}

Ciclos de Mejora en el Aula (2020). Experiencias de Innovación Docente de la US Esta obra se distribuye con la licencia Creative Commons 


\begin{tabular}{|c|c|c|c|c|}
\hline $\begin{array}{l}\text { Reflexión en } \\
\text { torno a una } \\
\text { noticia }\end{array}$ & 1h & $\begin{array}{l}\text { El alumnado realiza la lectura de } \\
\text { la noticia 'El enigma del poeta } \\
\text { con } 900.000 \text { seguidores' con el } \\
\text { fin de adquirir una perspectiva } \\
\text { crítica sobre el funcionamiento de } \\
\text { la industria editorial. Realiza un } \\
\text { resumen de las ideas esenciales } \\
\text { del texto y aporta una breve } \\
\text { reflexión sobre la influencia } \\
\text { de las redes sociales en la } \\
\text { comercialización editorial. }\end{array}$ & Tarea EV & C \\
\hline $\begin{array}{l}\text { Galería de } \\
\text { videocreación } \\
\text { poética }\end{array}$ & - & $\begin{array}{l}\text { El problema inicial ¿Cómo } \\
\text { llevar la poesía al aula? queda } \\
\text { resuelto mediante los trabajos } \\
\text { de innovación didáctica basados } \\
\text { en la videocreación poética } \\
\text { desarrollada por los propios } \\
\text { estudiantes. }\end{array}$ & $\begin{array}{l}\text { Galería EV y } \\
\text { redes sociales }\end{array}$ & C \\
\hline
\end{tabular}

\section{Cuestionario inicial-final de seguimiento de la progresión de las ideas de los estudiantes}

Con el objeto de valorar la progresión en los aprendizajes de los estudiantes se ha diseñado el cuestionario inicial-final ya mencionado, para poder medir y evaluar los modelos mentales e ideas que predominan en los alumnos y alumnas antes y después de aplicar el CIMA. El cuestionario es introducido al alumnado insistiendo en su utilidad para enriquecer nuestro proceso de enseñanza-aprendizaje y las posibilidades que este brinda para adaptar las clases a sus particularidades, ya que se trata de una suerte de "foto fija" que nos permite conocer el punto de partida y finalización del grupo. De igual modo, se explicita su formato anónimo - solo se solicita un pseudónimo-y su carácter no evaluable para la calificación final con el fin de que lo respondan con calma y sinceridad (y sin buscar información en fuentes externas).

El instrumento de recogida de ideas ha sido el siguiente:

Ciclos de Mejora en el Aula (2020). Experiencias de Innovación Docente de la US Esta obra se distribuye con la licencia Creative Commons 
1. Define la poesía en 3 palabras ¿Qué hace que un texto sea poético y no de otro género literario? Razona tu respuesta.

2. ¿Crees que la poesía está presente en nuestra vida cotidiana? En caso afirmativo pon algún ejemplo con tus propias palabras.

3. ¿Te consideras lector/a habitual de poesía? ¿Por qué?

4. ¿Tienes autores de poesía favoritos/as? ¿Cuáles?

5. Nombra al menos 3 autoras/es de poesía española e hispanoamericana de cualquier época histórica. Si sabes más, añádelos.

6. ¿Qué autora española es considerada la "poeta de los niños"?

7. Imagina que eres docente del CEIP Tomás de Ybarra, situado en la localidad de Tomares, Sevilla. La directora del centro reúne al claustro del que formas parte para notificaros que ante las graves carencias en el nivel lectoescritor del alumnado la Junta de Andalucia va a financiaros un Plan de Fomento de la Lectoescritura. Tú eres el/la responsable del género lírico ¿Qué medidas concretas (al menos 3) propondrías para que los niños y niñas aprendan a leer y escribir poesía? Explica cada una de ellas en detalle.

8. ¿Crees que el lenguaje poético ayuda al desarrollo cognitivo de niños y niñas? Justifica tu respuesta

9. En tu opinión, ¿puede un/a docente dar clase de poesía en Primaria sin ser lector habitual de este género? Justifica tu respuesta.

10. ¿Crees que cualquier texto que se autodenomine poesía lo es? Razona tu respuesta.

\section{Diario de las sesiones}

Se presenta a continuación el diario de las cinco sesiones en las que se ha aplicado el presente ciclo de mejora. 
A fin de atestiguar cuál ha sido el desarrollo real de las actividades diseñadas expuestas con anterioridad se aporta un relato sucinto de su progresión.

Aunque el resultado final de la evaluación del ciclo ha sido satisfactorio, el desarrollo de las sesiones en sí ha sido complejo y frustrante a ratos no solo por tratarse de mi primera vez como docente universitaria, sino porque además el "aula" de la que he dispuesto se circunscribía al reducto de los materiales que yo colgara en la plataforma Enseñanza Virtual - al tratarse de una clase en modalidad asíncrona-. Es decir, nunca iba a disponer de un espacio presencial ni virtual en el que interactuar en directo con mis estudiantes debido a que, como avanzaba al inicio, estas prácticas se solapaban con otra materia. Siendo esta la situación de partida, es necesario mencionar que obtuve dos clases extras solicitadas al compañero encargado de impartir la teoría de la asignatura Literatura Española. De este modo, el presente CIMA se aplicó en cinco sesiones dedicadas al género lírico:

La primera sesión -11 de noviembre de 2020- se presentó a partir de un vídeo propio de explicación e introducción al módulo práctico de poesía. Lo acompañé de una presentación para aquellos que no visionasen el vídeo, donde ya daba las pautas del proyecto final al que habían de enfrentarse al término del ciclo. Asimismo, colgué el Cuestionario Inicial $(\mathrm{Cl})$-diseñado en Google Formspara que fuese rellenado bajo anonimato. Como primera tarea, además del $\mathrm{Cl}$, creé un hilo de debate en foro denominado La poesía, un arma cargada de futuro con el fin de que expusieran sus pareceres en torno a los beneficios de la poesía para el desarrollo cognitivo de los niños y niñas y los principales obstáculos que atisban para su incorporación en el aula. Avisé por correo electrónico y por EV del comienzo del nuevo módulo, pero no recibí feedback del alumnado. En general, la mayoría de los participantes en el hilo de debate reconocían la importancia de la poesía para el desarrollo cognitivo infantil. En cuanto 
a los problemas que preveían destacaban la complejidad de hacer atractivo un género que puede crear rechazo si no se imparte correctamente, por lo que precisamente la conversación se dirigía a la pregunta clave: ¿Cómo llevar la poesía al aula? Así sintetizaba una alumna sus preocupaciones al respecto: En muchas ocasiones hemos observado, e incluso vivido, cómo la lírica es enseñada de una forma que no concuerda con la edad en la que se trabaja, otorgándole así (inconscientemente) una connotación negativa. A su vez, desde mi perspectiva, pienso que es un género que se da "de pasada", pues más que trabajar e intentar crear una motivación, se muestra una gran cantidad de contenido quedando reducido este género al estudio memorizado de una teoría concreta y el análisis métrico de los versos. Esto que hace que no se pueda trabajar correctamente y no se consiga un verdadero aprendizaje significativo.

La segunda sesión del ciclo -18 de noviembre-discurrió de nuevo como "clase a ciegas" de modo que deposité una presentación en la plataforma - ¿Está la poesía presente en nuestro día a día?- en la que les proporcionaba referencias visuales para que indagaran sobre la poesía visual del fotógrafo Chema Madoz; ejemplos de creaciones de videopoesía; y dejé que descubrieran las relaciones entre música y poesía a partir de la creación de una playlist colaborativa en Spotify llamada Poemas hechos canciones. Asimismo, les proporcioné la lectura voluntaria de Poesía y música, relaciones cómplices (Cantizano, 2005).

La tercera sesión -20 de noviembre-, cedida por el área de teoría, se celebró en Blackboard Collaborate por lo que pude al fin conocer (al menos la voz) de mis alumnos y alumnas. No obstante, al tratarse de un viernes por la tarde la asistencia (no obligatoria) fue muy baja. Trabajamos de modo teórico Las 10 características fundamentales del género lírico y lo complementamos con pausas 
prácticas dedicadas a la escritura de un haiku y de una greguería. Recomendé que visionaran el documental sobre la vida de Gloria Fuertes que les dejé en plataforma con el fin de que la clase siguiente fuera más fluida.

Durante la cuarta sesión -23 de noviembre-cundió el caos. Se trataba nuevamente de una sesión cedida en la que podía interactuar en Blackboard y a la que asistió casi toda la clase al completo. Comencé recordando la diapositiva del planteamiento inicial de la materia para nuevamente incidir en los plazos de entrega y la modalidad en la que veníamos trabajando desde el día 11 de noviembre. Imagino que gran parte no habría accedido a dicho material, pues los estudiantes se abrumaron al saber que la entrega del videopoema se realizaba el día 27. Dado que tenían más entregas de otras asignaturas esa misma semana, atrasé la entrega al día 28. Este periodo de aclaraciones y estrés estudiantil copó 20 minutos de la clase, lo cual no estaba previsto. Ese día terminamos Las $10 \mathrm{ca-}$ racterísticas fundamentales del género lírico, pues me había quedado pendiente explicar el soneto en la anterior sesión. El espacio que finalmente quedó dedicado a presentar la vida y obra de la poeta Gloria Fuertes fue muy escaso (25 minutos) aunque se debía complementar con el documental anteriormente expuesto. La tarea que debían realizar era el comentario del poema Nota autobiográfica a partir de las guías de comentario que les dejé en EV. Asimismo, seleccioné una gran parte de El libro de Gloria Fuertes. Antología de poemas y vida (2017), tanto de su poesía como de imágenes y dibujos realizados por la propia Gloria, así como un recopilatorio de declaraciones de la autora sobre su mirada y acercamiento a la creación poética. Esto último lo leímos juntos en clase para intercalar con los datos sobre su vida que yo les iba proporcionando.

Para la última sesión -25 de noviembre- les mandé la lectura y reflexión sobre las relaciones del marketing y las 
redes sociales con la industria editorial a través de la noticia El enigma del poeta con 900.000 seguidores, publicada en El País.

Recibí muy pocas consultas sobre el proyecto final de videocreación, que era lo que más alterados les tenía. Pese a mi repetición en las dos clases impartidas en Blackboard Collaborate así como mi insistencia en los correos electrónicos y en las presentaciones, nadie me solicitó una tutoría online. En resumen, las circunstancias de emergencia sanitaria en las que se ha desarrollado este CIMA, junto a las limitaciones del modelo de docencia asíncrona impuesto, han marcado su desarrollo, haciendo que este resultara un tanto agridulce en lo que he venido denominando como "clase a ciegas". No obstante, los proyectos finales del alumnado, así como sus valoraciones, me llenan de esperanza para continuar mejorando y aprendiendo con ellos y ellas.

\section{Evaluación del aprendizaje de los estudiantes}

Para poder evaluar la progresión del aprendizaje de los estudiantes se ha empleado la herramienta del cuestionario inicial y final, el cual queda representado gráficamente mediante las siguientes escaleras de aprendizaje (Porlán, 2017). Cabe señalar que el resto de los materiales que los estudiantes han entregado también han sido tenidos en cuenta en el proceso de evaluación continua de la asignatura. No obstante, no se deparará en ellos por falta de espacio. En líneas generales, los estudiantes han evolucionado ascendiendo en la escalera de aprendizaje en la mayoría de las preguntas por lo que los resultados son satisfactorios. Partíamos con un nivel base bajo en cuanto a conocimiento y lectura poética, lo cual hacía que las expectativas fueran bajas. Un 78,94\% de la clase afirmaba que la poesía está presente su vida cotidiana, haciendo referencia a

Ciclos de Mejora en el Aula (2020). Experiencias de Innovación Docente de la US Esta obra se distribuye con la licencia Creative Commons 
medios de cultura de masas tales como la música, el cine o la publicidad. Sin embargo, la inmensa mayoría - 84,21\%reconocía su desapego hacia su lectura, aludiendo a su grado de dificultad e incomprensión y apuntando hacia una carencia en su proceso de aprendizaje que se ha presentado a lo largo de las distintas etapas de su proceso educativo. De igual modo cabe señalar que en un inicio, entre los autores favoritos del alumnado se encontraban: Pablo Neruda, Federico García Lorca, Gustavo Adolfo Bécquer, Mario Benedetti y Antonio Machado. Resulta reseñable que ninguna autora fue mencionada como favorita en el grupo. No obstante, tras la finalización del ciclo un 37,5\% del estudiantado señaló a Gloria Fuertes como poeta preferida -curiosamente un 36,85\% desconocía a la "poeta de los niños" previamente-. A día de hoy, soy fan de Gloria Fuertes. Hace un par de semanas no lo era", afirma una alumna. De entrada, los estudiantes que eran capaces de aportar una definición elaborada de la poesía como creación literaria con fines estéticos, con capacidad de expresar emociones y sentimientos y/o vehicular la crítica social, y además, señalar características propias -como su escritura en verso y prosa, la composición métrica, el ritmo, la rima y el empleo de recursos literarios- solo ascendía al 10,52\% de la clase. Al finalizar el CIMA un 25\% se encuentra en este nivel del conocimiento.

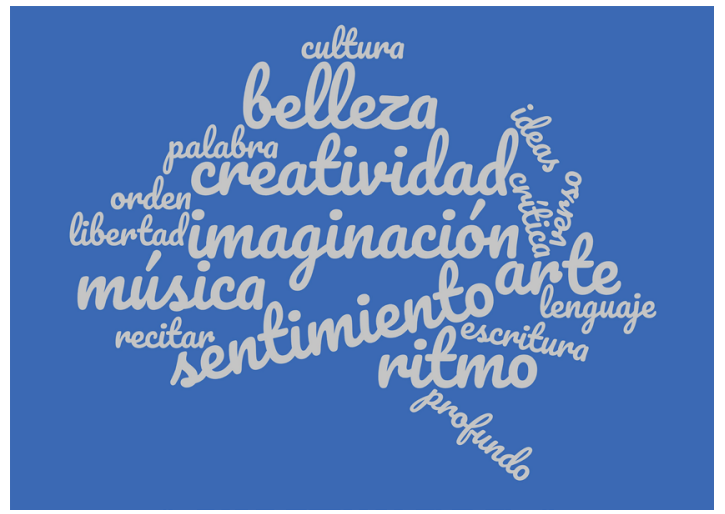

Figura 3. Nube de ideas de la definición de la poesía por parte del alumnado

Ciclos de Mejora en el Aula (2020). Experiencias de Innovación Docente de la US Esta obra se distribuye con la licencia Creative Commons 
Se presenta a continuación, a título de ejemplo, dos escaleras de aprendizaje.

Pregunta 7. Imagina que eres docente del CEIP Tomás de Ybarra, situado en la localidad de Tomares, Sevilla. La directora del centro reúne al claustro del que formas parte para notificaros que, ante las graves carencias en el nivel lectoescritor del alumnado, la Junta de Andalucía va a financiaros un Plan de Fomento de la Lectoescritura. Tú eres el/la responsable del género lírico ¿Qué medidas concretas (al menos 3) propondrías para que los niños y niñas aprendan a leer y escribir poesía? Explica cada una de ellas en detalle.

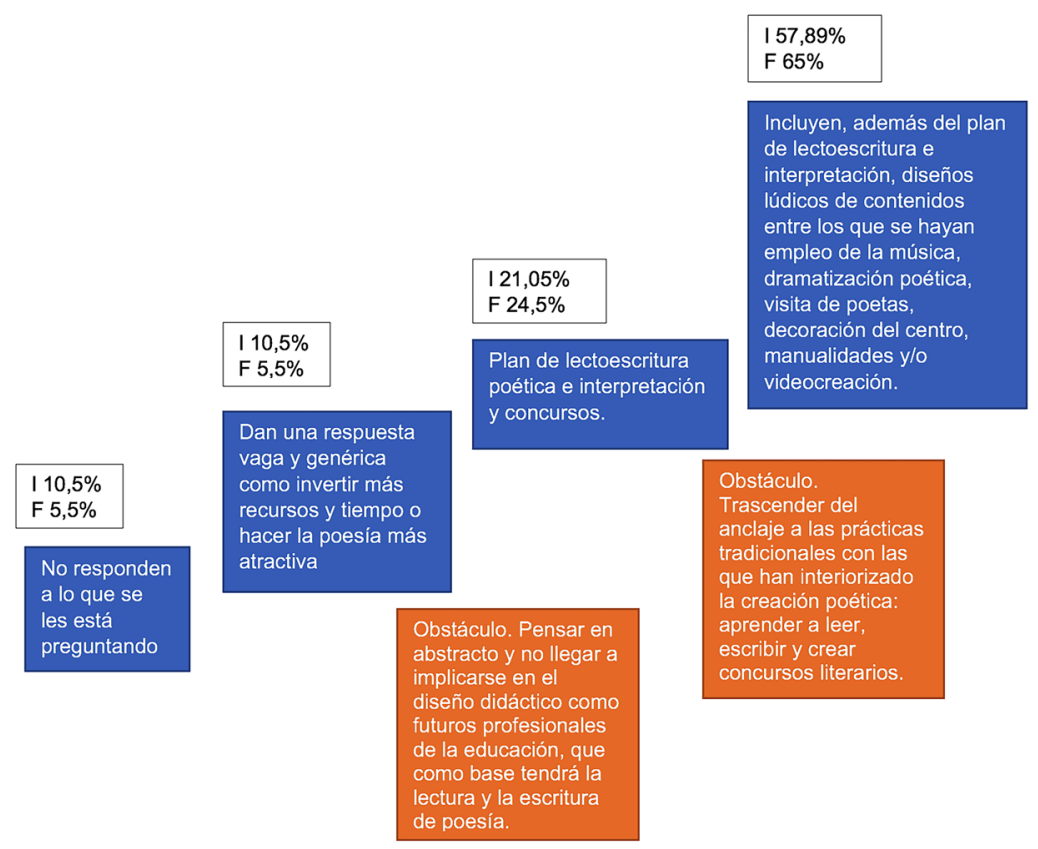

Figura 4. Escalera de aprendizaje de la pregunta 7

La escalera de aprendizaje presentada nos muestra que, en cuanto a las medidas para implementar un Plan de Fomento de la Lectoescritura en el área de poesía en un centro concreto, el alumnado ha elevado su conocimiento

Ciclos de Mejora en el Aula (2020). Experiencias de Innovación Docente de la US Esta obra se distribuye con la licencia Creative Commons 
con un grado de impacto muy leve, lo cual viene a determinar que han afianzado sus planteamientos didácticos de partida sin grandes cambios destacables, los cuales ya se situaban mayoritariamente en los dos niveles superiores de aprendizaje. Al finalizar el ciclo, el 65\% de la clase se encuentra en el máximo nivel de conocimiento por lo que es capaz de realizar un diseño didáctico integrador, creativo y dinámico que articule el género lírico como materia viva más allá del poemario.

Pregunta 10. ¿Crees que cualquier texto que se autodenomine poesía lo es? Reflexiona atendiendo a las relaciones entre marketing y redes sociales y la industria editorial.

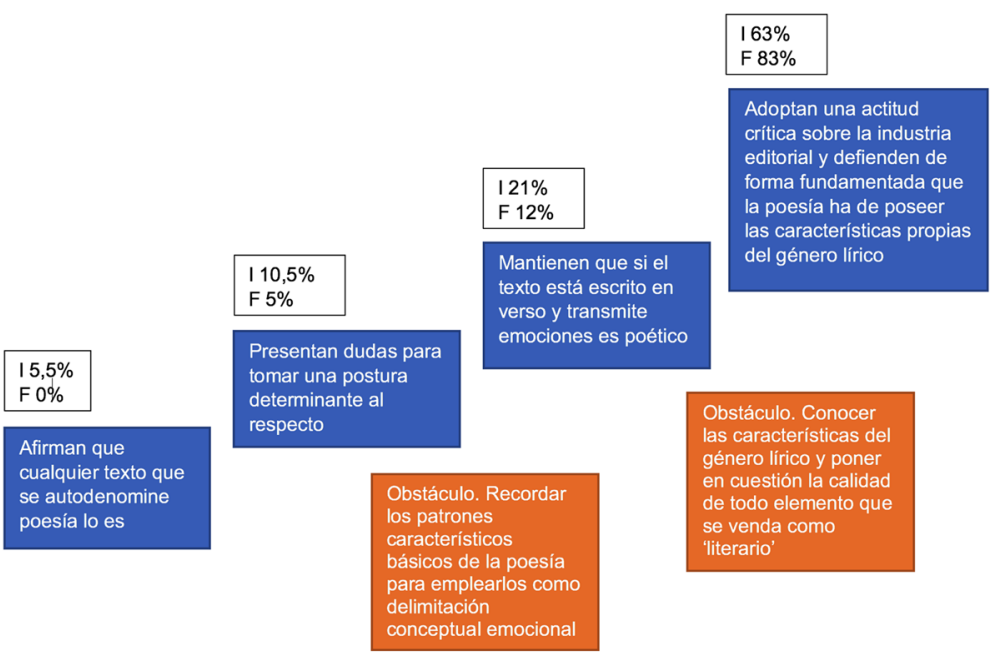

Figura 5. Escalera de aprendizaje de la pregunta 10

La escalera nos muestra un avance progresivo y notorio en la escalada hacia el conocimiento del grupo, que en este caso se materializa en la adopción de una postura crítica ante la industria editorial de un total del 83\% del estudiantado al finalizar el ciclo. Así, los alumnos y alumnas se muestran recelosos hacia las técnicas llevadas a cabo en redes sociales con el fin de comercializar productos 
estéticamente poéticos de calidad literaria cuestionable. Todo lo cual constata el exitoso desarrollo de la primera actividad de contraste teórica (AC T) en la que se abordaron Las 10 características fundamentales del género lírico (sesión 2) así como la actividad de conclusión (C) consistente en la lectura de una noticia de prensa (sesión 5).

Por último, es destacable el buen desempeño del estudiantado dentro de las adversas circunstancias en las que se han desarrollado las sesiones. A la distancia de partida hacia el género lírico como lectores se sumaba la distancia física e incluso virtual fruto de la asincronía, dinamitando así cualquier atisbo de interacción en streaming. La única vía posible para solventar tal grado de distanciamiento fue un uso sistemático del correo electrónico entre alumnado y profesora (reproduciendo así los aprendizajes adquiridos por mi parte en el FIDOP). Pese a las quejas por el número de tareas, me ha impresionado la implicación y la creatividad depositada en el proyecto final. Realmente me ha parecido interesante, al tratar la poesía desde otra perspectiva a la que estamos acostumbrados; además, la idea del videopoema me ha resultado bastante atractiva, aunque no voy a negar que al principio sentí cierto nerviosismo por no saber cómo enfocarlo, expone una alumna en el cuestionario final. Los videopoemas serán compartidos en redes sociales a fin de proveerse entre sí de materiales originales e inspiradores para su futuro desempeño profesional. Todo ello, pone de manifiesto que cuando el alumnado ve la utilidad en lo que está haciendo podemos lograr un cambio sustancial en su actitud, alcanzando así un aprendizaje significativo y perdurable en el tiempo.

\section{Evaluación del CIMA}

La evaluación del CIMA ha sido positiva, sin embargo, el análisis de los resultados obtenidos determina que es necesario mantener y mejorar algunos aspectos para el próximo curso.

Ciclos de Mejora en el Aula (2020). Experiencias de Innovación Docente de la US Esta obra se distribuye con la licencia Creative Commons 


\section{Aspectos a mantener:}

- El modelo metodológico presentado se ha desarrollado correctamente y ha resultado sumamente útil para realizar una propuesta coherente de la secuencia de actividades. Si bien, puede mejorarse e implementarse en el siguiente CIMA.

- El diario de las sesiones, ya que ha demostrado ser una herramienta provechosa que conservaré en el futuro.

- La articulación de las sesiones en torno a la resolución de un problema (y subproblemas) de corte pragmático, lo cual constata que el diseño del mapa de contenidos ha sido acertado.

- Evaluación de las ideas del alumnado mediante cuestionarios iniciales y finales y representación mediante escaleras de aprendizaje.

\section{Aspectos a mejorar:}

- La mejora de la impartición de la asignatura Literatura Española pasa por una necesaria coordinación y consenso entre el profesorado de teoría y práctica con el fin de mejorar la calidad de la enseñanza. No se descarta el diseño y aplicación de un CIMA integrado entre ambas áreas. El alumnado solicitó clases más prácticas y menos tareas, lo cual puede solventarse con un diseño en conjunto por parte de los docentes implicados.

- Es necesario modificar el cuestionario eliminando las preguntas 2, 3, 4, 5, 6 y 9, ya que solo sirven para contextualizar a los estudiantes. Dicha información puede obtenerse mediante otras tareas con el fin de reducir el tiempo del cuestionario, ya que resulta demasiado largo y ello puede afectar a la obtención fiel y representativa de una imagen panorámica del nivel del grupo.

Ciclos de Mejora en el Aula (2020). Experiencias de Innovación Docente de la US Esta obra se distribuye con la licencia Creative Commons 
- Sería recomendable mandar un calendario de tareas desde el día de la presentación con el fin de facilitar la gestión temporal al alumnado y evitar confusiones y "atascos" indeseados.

- Adaptar el CIMA al tiempo disponible con un enfoque realista que no atosigue de tareas al alumnado. Es preferible reducir el contenido y profundizarlo a pasar deprisa por él.

Ciclos de Mejora en el Aula (2020). Experiencias de Innovación Docente de la US Esta obra se distribuye con la licencia Creative Commons 
Palabras clave: Docencia Universitaria, Experimentación Docente Universitaria, Grado en Educación Primaria, Gloria Fuertes, Videopoema.

Keywords: University Teaching, University Teaching Experimentation, Bachelor's Degree in Primary School Education, Gloria Fuertes, Video poetry.

\section{Referencias bibliográficas}

Arriaga, M. (2020). Literatura y mujeres: querellas, genealoglas y sororidades. En I. Liberia-Vaya y B. Sánchez-Gutiérrez (Coords.). Aquelarre. La emancipación de las mujeres en la cultura de masas, (pp. 39-56). Sevilla: Advook.

Bain, K. (2004). Lo que hacen los mejores profesores universitarios. Valencia: Universitat de Valencia.

Cantizano, B. (2005). Poesía y música, relaciones cómplices. Revista de Estudios Literarios, no 30. Disponible en: http://webs.ucm.es/info/especulo/numero30/poemusi.html

De Cascante, J. (Ed.), (2017). El libro de Gloria Fuertes: antología de poemas y vida. Barcelona: Blackie Books.

Finkel, D. (2008). Dar clase con la boca cerrada. Valencia: Universitat de Valencia.

Porlán, R. (Coord.), (2017). Enseñanza universitaria. Cómo mejorarla. Madrid: Ediciones Morata.

Ciclos de Mejora en el Aula (2020). Experiencias de Innovación Docente de la US Esta obra se distribuye con la licencia Creative Commons 